\title{
Clinical Characteristics of COVID-19 Patients With
}

\section{Digestive Symptoms in Hubei, China: A Descriptive, Cross-Sectional, Multicenter Study}

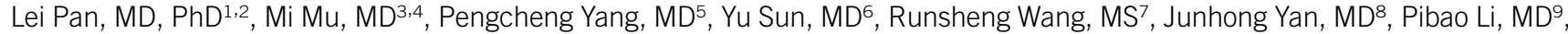 \\ Baoguang $\mathrm{Hu}, \mathrm{MD}, \mathrm{PhD}^{10}$, Jing Wang, $\mathrm{MS}^{1}$, Chao Hu, MS${ }^{7}$, Yuan Jin, MD ${ }^{6}$, Xun Niu, MD ${ }^{6}$, Rongyu Ping, MD², Yingzhen Du, MD, \\ Tianzhi Li, MD², Guogang Xu, MD, PhD², Qinyong Hu, MD ${ }^{5}$ and Lei Tu, MD, PhD ${ }^{11}$
}

OBJECTIVE: $\quad$ Since the outbreak of Coronavirus Disease 2019 (COVID-19) in December 2019, various digestive symptoms have been frequently reported in patients infected with the virus. In this study, we aimed to further investigate the prevalence and outcomes of COVID-19 patients with digestive symptoms.

METHODS: $\quad$ In this descriptive, cross-sectional, multicenter study, we enrolled confirmed patients with COVID-19 who presented to 3 hospitals from January 18,2020, to February 28, 2020. All patients were confirmed by real-time polymerase chain reaction and were analyzed for clinical characteristics, laboratory data, and treatment. Data were followed up until March 18, 2020.

RESULTS: In the present study, 204 patients with COVID-19 and full laboratory, imaging, and historical data were analyzed. The average age was 52.9 years (SD \pm 16 ), including 107 men and 97 women. Although most patients presented to the hospital with fever or respiratory symptoms, we found that 103 patients $(50.5 \%)$ reported a digestive symptom, including lack of appetite ( 81 [78.6\%] cases), diarrhea (35 [34\%] cases), vomiting (4 [3.9\%] cases), and abdominal pain (2 [1.9\%] cases). If lack of appetite is excluded from the analysis (because it is less specific for the gastrointestinal tract), there were 38 total cases $(18.6 \%)$ where patients presented with a gastrointestinal-specific symptom, including diarrhea, vomiting, or abdominal pain. Patients with digestive symptoms had a significantly longer time from onset to admission than patients without digestive symptoms (9.0 days vs 7.3 days). In 6 cases, there were digestive symptoms, but no respiratory symptoms. As the severity of the disease increased, digestive symptoms became more pronounced. Patients with digestive symptoms had higher mean liver enzyme levels, lower monocyte count, longer prothrombin time, and received more antimicrobial treatment than those without digestive symptoms.

DISCUSSION: We found that digestive symptoms are common in patients with COVID-19. Moreover, these patients have a longer time from onset to admission, evidence of longer coagulation, and higher liver enzyme levels. Clinicians should recognize that digestive symptoms, such as diarrhea, are commonly among the presenting features of COVID-19 and that the index of suspicion may need to be raised earlier in at-risk patients presenting with digestive symptoms. However, further large sample studies are needed to confirm these findings.

Am J Gastroenterol 2020;115:766-773. https://doi.org/10.14309/ajg.0000000000000620

${ }^{1}$ Department of Respiratory and Critical Care Medicine, Binzhou Medical University Hospital, Binzhou, China; ${ }^{2}$ The Second Medical Center \& National Clinical Research Center for Geriatric Diseases, Chinese PLA General Hospital, Beijing, China; ${ }^{3}$ Medical College of PLA, Chinese PLA General Hospital, Beijing, China; ${ }^{4}$ Department of Respiratory Medicine, The Eighth Medical Center of PLA General Hospital, Beijing, China; ${ }^{5}$ Cancer Center, Renmin Hospital of Wuhan University, Wuhan, China; ${ }^{6}$ Department of Otorhinolaryngology, Union Hospital, Tongji Medical College, Huazhong University of Science and Technology, Wuhan, China; ${ }^{7}$ Department of Respiratory Medicine, The Second Medical Center and National Clinical Research Center for Geriatric Diseases, Medical College of PLA, Chinese PLA General Hospital, Beijing, China; ${ }^{8}$ Department of Ultrasound, Binzhou Medical University Hospital, Binzhou, China; ${ }^{9}$ Department of Critical Care Medicine, Shandong Provincial Third Hospital, Jinan, China; ${ }^{10}$ Department of Gastrointestinal Surgery, Binzhou Medical University Hospital, Binzhou, China; ${ }^{11}$ Division of Gastroenterology, Union Hospital, Tongji Medical College, Huazhong University of Science and Technology, Wuhan, China. Correspondence: Lei Tu, MD, PhD.

E-mail: tulei_1985@126.com. Qinyong Hu, MD. E-mail: rm001223@whu.edu.cn. Guogang Xu, MD, PhD. E-mail: guogang_xu@163.com.

Received March 18, 2020; accepted XXXX; published online April 14, 2020 


\section{INTRODUCTION}

On January 7, 2020, a novel coronavirus was isolated and named as severe acute respiratory syndrome coronavirus 2 (SARS-CoV-2) by the International Committee on Taxonomy of Viruses (ICTV) in the wake of an outbreak of pneumonia of unknown cause in Wuhan city, China $(1,2)$. This pneumonia was called Coronavirus Disease 2019 (COVID19) by the World Health Organization on February 11, 2020. As of this writing, the COVID-19 outbreak has become a pandemic that is threatening global health, undermining the global economy, and destabilizing societies across the world (3-5).

It is well established that most patients with COVID-19 have fever along with respiratory signs and symptoms, such as cough and dyspnea (6-9). To date, there is some uncertainty about the prevalence of extrapulmonary symptoms, such as those arising from the gastrointestinal tract. However, with the evolution of the pandemic and the accumulation of case data, we are now able to describe the initial clinical presentations of patients with COVID-19; and our experience is revealing that digestive symptoms are very common (10). In particular, our initial observations with COVID-19 indicate that many patients present initially with diarrhea, anorexia, and vomiting, not necessarily with respiratory symptoms at first. In this study, we enrolled patients confirmed to have COVID-19 from 3 hospitals in Hubei province and investigated the prevalence, clinical characteristics, and outcomes of COVID-19 patients with vs without digestive symptoms.

\section{METHODS}

\section{Study design and participants}

This descriptive, cross-sectional, multicenter study was conducted in China, from January 18, 2020, to February 28, 2020. All patients were recruited from 3 hospitals in Hubei province, including Wuhan Hanan Hospital, Wuhan Union Hospital, and Huanggang Central Hospital. This study was approved by the Ethics Committee of the above 3 hospitals. We randomly selected 310 patients with pneumonia of unknown cause from general wards and intensive care units (ICUs) in the 3 hospitals as the initial study population.

We applied 2 inclusion criteria: (i) all adult patients were confirmed by real-time polymerase chain reaction and were diagnosed as having COVID-19 according to WHO interim guidance and (ii) all patients who underwent chest computerized tomography (CT) and complete panel of routine laboratory tests, including compete blood count, urinalysis, blood biochemistry, and blood coagulation function. Patients who did not meet the above inclusion criteria were excluded from the study.

\section{Procedures}

The epidemiological history, demographics data, clinical characteristics, laboratory data, treatment programs, and outcome measures were obtained from the patients' medical records. Clinical outcomes were followed up to March 18, 2020. Data were collected as comprehensively as possible through a combination of chart review and, when necessary, through communication with attending doctors and other medical workers to fill in the missing data. All data were separately extracted by 2 authors (L.T. and M.M.). Throat swab specimens from the upper respiratory tract obtained from all patients at admission were immediately maintained in a viral transport medium and were tested to confirm COVID-19 by real-time polymerase chain reaction (11). In addition, other respiratory viruses including influenza A virus, influenza B virus, and respiratory syncytial virus were also examined. All patients underwent chest CT.

\section{Outcome data}

We extracted the epidemiological history (i.e., clear contact history and unclear contact history), demographic data, clinical characteristics including respiratory symptoms and digestive symptoms on admission, comorbidities, laboratory data, treatment programs, and clinical outcomes (discharged and died).

\section{Statistical analysis}

Descriptive data were presented as mean $( \pm S D)$ for normally distributed continuous variables and as median with interquartile range for non-normally distributed data. Categorical variables were presented as percentages. For laboratory results, we also assessed whether the measurements were outside the normal range. All statistical analyses were performed using SPSS version 20 (SPSS, Chicago, IL). Two independent samples were tested by the Student T-test; the analysis of variance or Kruskal-Wallis rank-sum test was used for comparison between multiple groups. The $\chi^{2}$ test was performed to compare count data, and a 2-tailed value of $P<0.05$ was considered statistically significant.

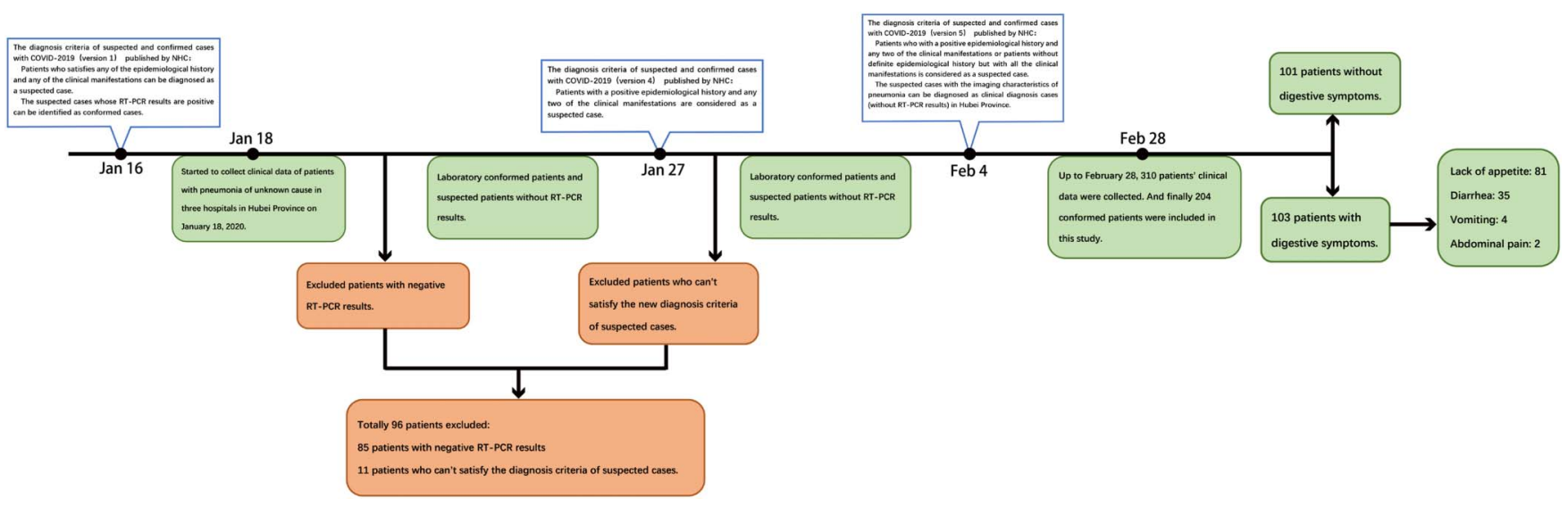

Figure 1. Patients flowchart. 
Table 1. Baseline characteristics and clinical outcomes of patients with COVID-19

\begin{tabular}{|c|c|c|c|c|c|c|c|c|}
\hline \multirow[b]{2}{*}{ Characteristics } & \multirow[b]{2}{*}{$\begin{array}{l}\text { All patients } \\
(n=204)\end{array}$} & \multirow{2}{*}{$\begin{array}{l}\text { Patients } \\
\text { without } \\
\text { digestive } \\
\text { symptoms } \\
(\mathrm{n}=101)\end{array}$} & \multirow{2}{*}{$\begin{array}{l}\text { Patients with } \\
\text { digestive } \\
\text { symptoms } \\
(n=103)\end{array}$} & \multirow[b]{2}{*}{$\begin{array}{c}P \\
\text { Value }\end{array}$} & \multicolumn{4}{|c|}{$\begin{array}{l}\text { Classification of patients with } \\
\text { digestive symptoms } \mathrm{s}^{\mathrm{a}}\end{array}$} \\
\hline & & & & & $\begin{array}{l}\text { Mild } \\
(n=1)\end{array}$ & $\begin{array}{l}\text { Moderate } \\
(n=65)\end{array}$ & $\begin{array}{l}\text { Severe } \\
(n=14)\end{array}$ & $\begin{array}{l}\text { Critical } \\
(n=23)\end{array}$ \\
\hline Age, years (mean [SD]) & $52.91 \pm 15.98$ & $53.61 \pm 16.10$ & $52.21 \pm 15.92$ & 0.533 & 24 & $47.91 \pm 14.85$ & $60.00 \pm 9.63$ & $60.87 \pm 16.44$ \\
\hline $\operatorname{Sex}(M / F)$ & $107 / 97$ & $52 / 49$ & $55 / 48$ & 0.784 & $1 / 0$ & $31 / 34$ & $7 / 7$ & $16 / 7$ \\
\hline Respiratory rate & $21.57 \pm 4.02$ & $21.02 \pm 3.08$ & $22.11 \pm 4.72$ & 0.053 & 23 & $20.62 \pm 2.04$ & $21.79 \pm 5.00$ & $26.48 \pm 7.06$ \\
\hline $\begin{array}{l}\text { Days from illness onset to } \\
\text { admission }\end{array}$ & $8.11 \pm 4.91$ & $7.26 \pm 4.20$ & $8.95 \pm 5.40$ & 0.013 & 1 & $8.35 \pm 4.02$ & $7.64 \pm 4.29$ & $11.78 \pm 8.00$ \\
\hline \multicolumn{9}{|l|}{ Epidemiological history } \\
\hline Clear contact history & $41(20.10 \%)$ & $18(17.82 \%)$ & $23(22.33 \%)$ & 0.422 & $1(100 \%)$ & $18(27.69 \%)$ & $3(21.43 \%)$ & $1(4.35 \%)$ \\
\hline Unclear contact history & $163(79.90 \%)$ & $83(82.18 \%)$ & $80(77.67 \%)$ & 0.422 & $0(0.00 \%)$ & $47(72.31 \%)$ & $11(78.57 \%)$ & $22(95.65 \%)$ \\
\hline \multicolumn{9}{|l|}{ Chronic medical illness } \\
\hline Respiratory system disease & $9(4.41 \%)$ & $2(1.98 \%)$ & $7(6.80 \%)$ & 0.182 & $1(100 \%)$ & $1(1.54 \%)$ & $2(14.29 \%)$ & $3(13.04 \%)$ \\
\hline Digestive system disease & $7(3.43 \%)$ & $3(2.97 \%)$ & $4(3.88 \%)$ & 1.000 & $0(0.00 \%)$ & $4(6.15 \%)$ & $0(0.00 \%)$ & $0(0.00 \%)$ \\
\hline $\begin{array}{l}\text { Cardiovascular system } \\
\text { disease }\end{array}$ & $44(21.57 \%)$ & $21(20.79 \%)$ & $23(22.3 \%)$ & 0.789 & $0(0.00 \%)$ & $10(15.38 \%)$ & $3(21.43 \%)$ & $10(43.48 \%)$ \\
\hline Nervous system disease & $5(2.45 \%)$ & $4(3.96 \%)$ & $1(0.97 \%)$ & 0.353 & $0(0.00 \%)$ & $1(1.54 \%)$ & $0(0.00 \%)$ & $0(0.00 \%)$ \\
\hline Endocrine system disease & $24(11.76 \%)$ & $14(13.86 \%)$ & $10(9.71 \%)$ & 0.357 & $0(0.00 \%)$ & $5(7.69 \%)$ & $1(7.14 \%)$ & $4(17.39 \%)$ \\
\hline Malignant tumor & $13(6.37 \%)$ & $5(4.95 \%)$ & $8(7.77 \%)$ & 0.410 & $0(0.00 \%)$ & $4(6.15 \%)$ & $0(0 \%)$ & $4(17.39 \%)$ \\
\hline \multicolumn{9}{|l|}{$\begin{array}{l}\text { Medical treatment after } \\
\text { admission }\end{array}$} \\
\hline Antibiotic treatment & $141(69.12 \%)$ & $62(61.39 \%)$ & 79 (76.70\%) & 0.018 & $0(0.00 \%)$ & $44(67.69 \%)$ & $14(100 \%)$ & $21(91.30 \%)$ \\
\hline Antifungal treatment & $10(4.90 \%)$ & $3(2.97 \%)$ & $7(6.80 \%)$ & 0.347 & $0(0.00 \%)$ & $2(3.08 \%)$ & $1(7.14 \%)$ & $4(17.39 \%)$ \\
\hline Antiviral treatment & $184(90.20 \%)$ & $90(89.11 \%)$ & $94(91.26 \%)$ & 0.605 & $0(0.00 \%)$ & 59 (90.77\%) & $12(85.71 \%)$ & $22(95.65 \%)$ \\
\hline Glucocorticoids & $80(39.22 \%)$ & $36(35.64 \%)$ & $44(42.72 \%)$ & 0.301 & $0(0.00 \%)$ & $17(26.15 \%)$ & $12(85.71 \%)$ & $15(65.22 \%)$ \\
\hline Nebulized $\alpha$-interferon & $96(47.06 \%)$ & $39(38.61 \%)$ & $57(55.34 \%)$ & 0.017 & $1(100.0 \%)$ & 40 (61.54\%) & $7(50.00 \%)$ & $9(39.13 \%)$ \\
\hline $\begin{array}{l}\text { Intravenous } \\
\text { immunoglobulin }\end{array}$ & $56(27.45 \%)$ & $17(16.83 \%)$ & $39(37.86 \%)$ & 0.001 & $0(0.00 \%)$ & $18(27.69 \%)$ & $7(50.00 \%)$ & $14(60.87 \%)$ \\
\hline $\begin{array}{l}\text { No. of cases transferred to } \\
\text { intensive care unit }\end{array}$ & $16(7.84 \%)$ & $10(9.90 \%)$ & $6(5.94 \%)$ & 0.279 & $0(0.00 \%)$ & $0(0.00 \%)$ & 2 (14.29\%) & $4(17.39 \%)$ \\
\hline \multicolumn{9}{|l|}{ Clinical outcome } \\
\hline Discharged & $168(82.35 \%)$ & $84(83.16 \%)$ & $84(81.55 \%)$ & 0.762 & $1(100 \%)$ & 65 (100\%) & $14(100 \%)$ & $4(17.39 \%)$ \\
\hline Died & $36(17.65 \%)$ & $17(16.83 \%)$ & $19(18.45 \%)$ & 0.762 & $0(0.00 \%)$ & $0(0.00 \%)$ & $0(0.00 \%)$ & 19 (82.61\%) \\
\hline \multicolumn{9}{|l|}{ Discharged } \\
\hline Total days in hospital & $17.06 \pm 9.02$ & $16.84 \pm 7.90$ & $17.28 \pm 10.03$ & 0.728 & 10.00 & $18.40 \pm 6.80$ & $\begin{array}{c}23.86 \pm \\
12.01\end{array}$ & $10.43 \pm 12.79$ \\
\hline Days of intensive care & $8.94 \pm 6.92$ & $10.00 \pm 7.90$ & $7.17 \pm 5.04$ & 0.448 & 1 & 1 & $8.50 \pm 3.54$ & $6.50 \pm 6.03$ \\
\hline
\end{tabular}

aThe classification of COVID-19 severity was mainly determined according to the COVID-19 prevention and control program issued by China's National Health Commission (http://www.nhc.gov.cn/). Mild patients were those without lesions in the chest computerized tomography (CT). Moderate patients were those with lesions in the chest CT.

\section{RESULTS}

\section{Patients' flow and baseline characteristics}

To build our final study sample, we began by randomly selecting 310 patients with pneumonia of unknown cause admitted to the general wards and ICU in the partner hospitals during the study period (January 18, 2020-February
28, 2020), which coincided with the initial outbreak of COVID-19 in the region. We excluded 96 patients who lacked complete data, such as no chest CT, missing nucleic acid of SARS-CoV-2 test, a negative SARS-CoV-2 test, or lacked a full set of laboratory data. This resulted in an analyzable population of 204 COVID-19-positive patients, of 


\title{
Frequency of COVID-19 patients with or without digestive
}

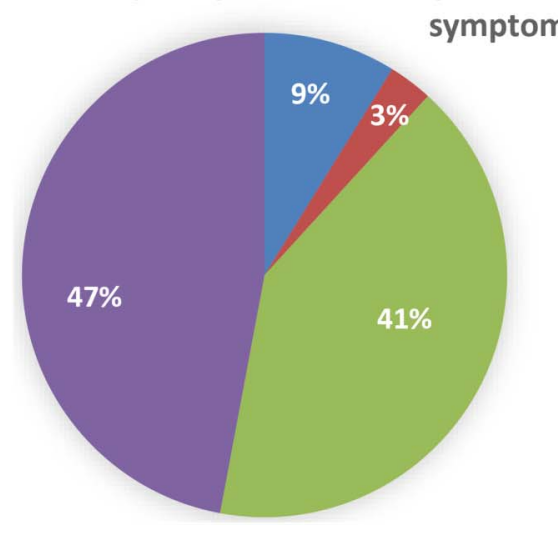

\author{
- Without digestive, nor respiratory \\ symptoms $(n=17)$ \\ With digestive symptoms, without \\ respiratory $(n=6$, most patients have \\ fever, except 1) \\ - With respiratory symptoms, without \\ digestive symptoms $(n=84)$ \\ With digestive and respiratory symptoms
} $(n=97)$

Figure 2. Frequency of COVID-19 patients with or without digestive symptoms.

whom 70 (34\%) were critically ill. The last follow-up at the time of writing this study was March 18, 2020. A detailed flowchart of participants is presented in Figure 1.

The baseline characteristics of 204 patients with COVID-19 are provided in Table 1 . The average age was 52.9 years $(\mathrm{SD} \pm$ 16.0), including 107 men and 97 women. The average time from symptom onset to hospital admission was 8.1 days ( $\mathrm{SD} \pm 4.9$ ). Based on epidemiological history, we found that most patients could not recall a clear history of a known exposure. There were $44(21.6 \%)$ patients with cardiovascular diseases, 24 (11.8\%) patients with endocrine system diseases, and others with respiratory diseases $(9[4.4 \%])$, malignant tumors (13 [6.3\%]), and other disorders, as shown in Table 1. After admission, there were $184(90.2 \%)$ patients receiving antiviral treatment (e.g., lopinavir-ritonavir), $141(69.1 \%)$ on antibiotics, $80(39.2 \%)$ on glucocorticoids, $96(47.1 \%)$ on nebulized $\alpha$-interferon, 56 $(27.5 \%)$ on intravenous immunoglobulin, and $10(4.9 \%)$ on antifungal treatment. In addition, 16 patients were transferred to the ICU (7.8\%), 168 were discharged (82.4\%), and $37(17.7 \%)$ died. Among the patients, the average hospital stay was 17 days $(\mathrm{SD} \pm 9.0)$, and the average length of stay in the ICU was 8.9 days $(\mathrm{SD} \pm 6.9)$.

\section{Prevalence and outcomes of patients with digestive symptoms}

The clinical features and medical treatment of COVID-19 patients with digestive symptoms are shown in Table 1. One hundred three patients (50.5\%) admitted to the hospital were found to present with one or more digestive symptoms. Of these 103 patients, 97 had developed respiratory symptoms along with digestive symptoms and 6 presented with only digestive symptoms in the absence of respiratory symptoms. Among the 101 patients without digestive symptoms, 84 presented only with respiratory symptoms and 20 neither had respiratory nor digestive symptoms as their chief complaint or as an accompanying symptom. Figure 2 shows a breakdown of these categories.

Patients with digestive symptoms had a significantly longer time from onset to hospital admission vs patients without digestive symptoms (9.0 days vs 7.3 days, $P=0.013$ ). In Table 2 , we found that patients with digestive symptoms had a variety of digestive manifestations, including lack of appetite (81 [78.64\%] cases), diarrhea (35 [34.0\%] cases), vomiting (4 [3.9\%] cases), and abdominal pain (2 [1.9\%] cases). If the nonspecific symptom of low appetite is excluded from the analysis, there were 38 total cases ( $18.6 \%$ of full sample) where patients presented with a gastrointestinal-specific symptom, including diarrhea, vomiting, or abdominal pain. Focusing only on diarrhea, there were 35 cases ( $17 \%$ of full sample) presenting with loose stools. Cases of diarrhea were usually not high volume or clinically severe, but more commonly presented as nondehydrating loose stools, typically up to thrice daily. We found that $69.2 \%$ and $100 \%$ of moderate and severe patients, respectively, had lack of appetite on presentation. As the severity of the disease increased, digestive symptoms become more pronounced. However, there was no significant difference in discharge time, days of intensive care, or mortality between the 2 groups.

In addition, we found that the number of patients with elevated ALT and AST $(>50 \mathrm{U} / \mathrm{L})$ were significantly higher in patients with digestive symptoms (ALT: 21 [20.4\%], AST: 17 [16.5\%]) than those without the digestive symptoms (ALT: 6 [5.9\%], AST: 5 [5.0\%]) $\left(P_{A L T}=0.002, P_{A S T}=0.008\right)$. Therefore, those patients with digestive symptoms were more likely to suffer liver injury, although the mean alanine aminotransferase and aspartate aminotransferase were in the normal range (Table 3). Monocyte counts were lower in patients with digestive symptoms. No significant differences were found in complete blood count, electrolytes, and kidney function when comparing patients with vs those without digestive symptoms. However, we did find that prothrombin time prolongation was more significant in patients with vs without digestive symptoms (13.1 vs 12.5 seconds), whereas other indicators of coagulation function were not significantly different. As compared to those with digestive symptoms, patients without digestive symptoms were less likely to receive antibiotic treatment $62(61.4 \%)$ vs $79(76.7 \%)$, interferon $39(38.6 \%)$ vs $57(55.3 \%)$, and immunoglobulin $17(16.8 \%)$ vs $39(37.9 \%)$.

\section{DISCUSSION}

The present study was conducted by reviewing the medical records of patients with COVID-19 from January 18, 2020, to February 28, 2020, in 3 heavily affected hospitals during the initial outbreak in Hubei province, where $83 \%$ of cases in China were reported. We found that digestive symptoms are a common complaint in patients with COVID-19. By the policy of the local government, Wuhan Union Hospital was deployed as the key 
Table 2. Summary of clinical features of COVID-19 patients with digestive symptoms

\begin{tabular}{|c|c|c|c|c|c|}
\hline Characteristics & $\begin{array}{l}\text { Patients } \\
(n=103)\end{array}$ & $\begin{array}{l}\text { Mild patients } \\
\qquad(n=1)\end{array}$ & $\begin{array}{l}\text { Moderate patients } \\
\qquad(n=65)\end{array}$ & $\begin{array}{l}\text { Severe patients } \\
\quad(n=14)\end{array}$ & $\begin{array}{l}\text { Critical patients } \\
\quad(n=23)\end{array}$ \\
\hline \multicolumn{6}{|l|}{ Symptoms } \\
\hline Lack of appetite & $81(78.64 \%)$ & $0(0.00 \%)$ & $45(69.23 \%)$ & $14(100 \%)$ & $22(95.65 \%)$ \\
\hline Diarrhea & 35 (33.98\%) & $1(100 \%)$ & $24(36.92 \%)$ & $3(21.43 \%)$ & $7(30.43 \%)$ \\
\hline Vomiting & $4(3.88 \%)$ & $0(0.00 \%)$ & $2(3.08 \%)$ & $1(7.14 \%)$ & $1(4.35 \%)$ \\
\hline Abdominal pain & $2(1.94 \%)$ & $0(0.00 \%)$ & $0(0.00 \%)$ & $0(0.00 \%)$ & $2(8.70 \%)$ \\
\hline Digestive diseases & $4(3.88 \%)$ & & & & \\
\hline Hepatitis B & $0(0.00 \%)$ & $0(0.00 \%)$ & $0(0.00 \%)$ & $0(0.00 \%)$ & $0(0.00 \%)$ \\
\hline Hepatitis C & $0(0.00 \%)$ & $0(0.00 \%)$ & $0(0.00 \%)$ & $0(0.00 \%)$ & $0(0.00 \%)$ \\
\hline fatty liver & $1(0.97 \%)$ & $0(0.00 \%)$ & $1(1.54 \%)$ & $0(0.00 \%)$ & $0(0.00 \%)$ \\
\hline Cirrhosis & $0(0.00 \%)$ & $0(0.00 \%)$ & $0(0.00 \%)$ & $0(0.00 \%)$ & $0(0.00 \%)$ \\
\hline Hepatic insufficiency & $1(0.97 \%)$ & $0(0.0 \%)$ & $1(1.54 \%)$ & $0(0.00 \%)$ & $0(0.00 \%)$ \\
\hline Gastritis & $1(0.97 \%)$ & $0(0.0 \%)$ & $1(1.54 \%)$ & $0(0.00 \%)$ & $0(0.00 \%)$ \\
\hline Gastroesophageal reflux disease & $1(0.97 \%)$ & $0(0.00 \%)$ & $1(1.54 \%)$ & $0(0.00 \%)$ & $0(0.00 \%)$ \\
\hline Ulcerative colitis & $0(0.00 \%)$ & $0(0.00 \%)$ & $0(0.00 \%)$ & $0(0.00 \%)$ & $0(0.00 \%)$ \\
\hline Peptic ulcer & $0(0.00 \%)$ & $0(0.00 \%)$ & $0(0.00 \%)$ & $0(0.00 \%)$ & $0(0.00 \%)$ \\
\hline Intestinal polyps & $0(0.00 \%)$ & $0(0.00 \%)$ & $0(0.00 \%)$ & $0(0.00 \%)$ & $0(0.00 \%)$ \\
\hline Crohn's disease & $0(0.00 \%)$ & $0(0.00 \%)$ & $0(0.00 \%)$ & $0(0.00 \%)$ & $0(0.00 \%)$ \\
\hline Colitis & $0(0.00 \%)$ & $0(0.00 \%)$ & $0(0.00 \%)$ & $0(0.00 \%)$ & $0(0.00 \%)$ \\
\hline Irritable bowel syndrome & $0(0.00 \%)$ & $0(0.00 \%)$ & $0(0.00 \%)$ & $0(0.00 \%)$ & $0(0.00 \%)$ \\
\hline Cholelithiasis & $0(0.00 \%)$ & $0(0.00 \%)$ & $0(0.00 \%)$ & $0(0.00 \%)$ & $0(0.00 \%)$ \\
\hline Cholecystitis & $0(0.00 \%)$ & $0(0.00 \%)$ & $0(0.00 \%)$ & $0(0.00 \%)$ & $0(0.00 \%)$ \\
\hline Cholangitis & $0(0.00 \%)$ & $0(0.00 \%)$ & $0(0.00 \%)$ & $0(0.00 \%)$ & $0(0.00 \%)$ \\
\hline Pancreatitis & $0(0.00 \%)$ & $0(0.00 \%)$ & $0(0.00 \%)$ & $0(0.00 \%)$ & $0(0.00 \%)$ \\
\hline \multicolumn{6}{|l|}{ Accompanying symptoms } \\
\hline Fever & 95 (92.23\%) & $1(100 \%)$ & $57(87.69 \%)$ & $14(100 \%)$ & $23(100 \%)$ \\
\hline Weakness & $54(52.42 \%)$ & $0(0.00 \%)$ & $28(43.08 \%)$ & $10(71.43 \%)$ & $16(69.57 \%)$ \\
\hline Muscle pain & $15(14.56 \%)$ & $0(0.00 \%)$ & $8(12.31 \%)$ & $2(14.29 \%)$ & $5(21.74 \%)$ \\
\hline
\end{tabular}

medical center to treat severe patients. Given the proximity of this hospital to the epicenter of the outbreak and the designation of this hospital to receive severe illness, patients in this sample were more critically ill than in other COVID-19 studies. The other 2 hospitals were designated to hospitalize mild-to-moderate COVID-19 patients: Wuhan Hannan Hospital, a secondary hospital $50 \mathrm{~km}$ from Union Hospital, and Huanggang Central Hospital, a newly-built hospital specifically constructed for COVID-19 patients, about $80 \mathrm{~km}$ away from Wuhan. Our initial purpose in this study was to investigate the prevalence and characteristics or extrapulmonary digestive symptoms that might otherwise be under-recognized, thus helping to bring attention to these symptoms to facilitate earlier recognition of COVID-19 and thus to offer earlier treatment before mild disease progresses to severe illness.

At the time of this writing in March 2020, the COVID-19 pandemic remains severe and expanding. In clinical practice, patients with COVID-19 are still mainly affected by the respiratory system but evidence of damage to other system organs has been reported $(12,13)$, and especially critical patients are susceptible to multiple organ dysfunction (14). Our results indicate that nearly one-half of patients with COVID-19 admitted to the hospital reported digestive symptoms, most commonly anorexia and diarrhea. This is important because if clinicians solely monitor for respiratory symptoms to establish case definitions for COVID-19, they may miss cases initially presenting with extrapulmonary symptoms or the disease may not be diagnosed later until respiratory symptoms emerge. This theory is supported by our finding that patients with digestive symptoms had a significantly longer time from onset to admission than those without digestive symptoms, possibly because they did not initially exhibit typical respiratory symptoms and thus did not receive timely diagnoses and treatment for COVID-19. Of note, it was reported that many medical staff in China were infected at the beginning of the epidemic. Although this was related to improper protection of medical personnel early on, it may also have resulted from failing to consider COVID-19 in the face of atypical extrapulmonary symptoms, especially those with digestive symptoms at the beginning of the outbreak. Less attention of digestive system symptoms by the public might also 
Table 3. Laboratory findings of patients with COVID-19 on admission

\begin{tabular}{|c|c|c|c|c|c|c|c|}
\hline \multirow[b]{2}{*}{ Characteristics } & \multicolumn{2}{|c|}{ All patients $(n=204)$} & \multicolumn{2}{|c|}{$\begin{array}{l}\text { Patients without } \\
\text { digestive symptoms } \\
(n=101)\end{array}$} & \multicolumn{2}{|c|}{$\begin{array}{l}\text { Patients with digestive } \\
\text { symptoms }(n=103)\end{array}$} & \multirow[b]{2}{*}{$P$ Value } \\
\hline & Mean & SD & Mean & SD & Mean & SD & \\
\hline White blood cell count, $\times 10^{9} / \mathrm{L}$ & 6.09 & 3.70 & 6.59 & 3.87 & 5.60 & 3.48 & 0.056 \\
\hline Neutrophil count, $\times 10^{9} / \mathrm{L}$ & 4.48 & 3.70 & 4.90 & 3.92 & 4.06 & 3.44 & 0.105 \\
\hline Hemoglobin, g/L & 128.08 & 18.52 & 128.77 & 18.40 & 127.41 & 18.70 & 0.601 \\
\hline Neutrophil ratio, \% & 67.85 & 16.21 & 68.36 & 15.26 & 67.35 & 17.16 & 0.658 \\
\hline Lymphocyte count, $\times 10^{9} / \mathrm{L}$ & 1.13 & 0.55 & 1.18 & 0.52 & 1.08 & 0.58 & 0.197 \\
\hline Monocyte count, $\times 10^{9} / \mathrm{L}$ & 0.42 & 0.22 & 0.46 & 0.23 & 0.39 & 0.20 & 0.021 \\
\hline Platelet count, $\times 10^{9} / \mathrm{L}$ & 201.14 & 88.38 & 195.73 & 84.09 & 206.44 & 92.49 & 0.388 \\
\hline Prothrombin time, s & 12.83 & 1.91 & 12.53 & 1.89 & 13.13 & 1.88 & 0.024 \\
\hline Activated partial thromboplastin time, $\mathrm{s}$ & 34.19 & 6.22 & 33.47 & 5.20 & 34.89 & 7.05 & 0.103 \\
\hline Fibrinogen, g/L & 4.40 & 1.57 & 4.27 & 1.41 & 4.54 & 1.71 & 0.220 \\
\hline Alanine aminotransferase, $\mathrm{U} / \mathrm{L}$ & 35.98 & 35.82 & 29.53 & 23.58 & 42.24 & 43.83 & 0.011 \\
\hline Aspartate aminotransferase, $\mathrm{U} / \mathrm{L}$ & 31.36 & 25.55 & 27.48 & 23.98 & 35.12 & 26.58 & 0.032 \\
\hline Glutamate/alanine aminotransferase & 1.10 & 0.56 & 1.09 & 0.53 & 1.10 & 0.59 & 0.899 \\
\hline Total bilirubin, $\mathrm{mmol} / \mathrm{L}$ & 13.65 & 10.26 & 13.46 & 8.11 & 13.83 & 12.03 & 0.797 \\
\hline Albumin, $g / L$ & 36.00 & 6.07 & 35.84 & 5.63 & 36.16 & 6.49 & 0.707 \\
\hline Blood nitrogen, $\mathrm{mmol} / \mathrm{L}$ & 5.11 & 2.76 & 5.14 & 2.92 & 5.08 & 2.62 & 0.877 \\
\hline Creatinine, $\mu \mathrm{mol} / \mathrm{L}$ & 75.54 & 26.87 & 76.21 & 26.51 & 74.88 & 27.33 & 0.725 \\
\hline Serum sodium, mmol/L & 138.42 & 4.26 & 138.26 & 4.70 & 138.56 & 3.81 & 0.617 \\
\hline Serum potassium, $\mathrm{mmol} / \mathrm{L}$ & 4.17 & 0.64 & 4.20 & 0.61 & 4.14 & 0.68 & 0.508 \\
\hline
\end{tabular}

contribute to the transmission inside the family or in the community.

There are many reasons why COVID-19 seems to cause digestive symptoms. First, SARS-CoV-2 is similar to SARS-CoV and can invade the human body by binding to the human angiotensin converting enzyme 2 (ACE-2) receptor, which causes liver tissue injury by the upregulation of ACE-2 expression in liver tissue caused by compensatory proliferation of hepatocytes derived from bile duct epithelial cells (15). Second, SARS-CoV-2 indirectly or directly damages the digestive system through an inflammatory response. The chain reaction of inflammatory factors and viremia may injure the digestive system. Studies reveal that viral nucleic acid is detected in stool samples in up to $53.4 \%$ of patients (16-18). Enteropathic viruses may directly damage the intestinal mucosa and cause digestive symptoms, but further research is needed to confirm this possibility. Third, the intestinal flora is colonized in the human intestine, and their numbers are astonishing and diverse. The intestinal flora plays a variety of important physiological roles in the body, such as affecting the body's nutritional metabolism, regulating the development and maturation of the body's immune system, and antibacterial effects (19). The virus itself may cause disorders of the intestinal flora, which could result in digestive symptoms. We are currently in the process of collecting stool samples for the testing of intestinal flora diversity to explore the role of intestinal flora in this disease. Finally, the intestine is the largest immune organ in the body. Changes in the composition and function of the digestive tract flora affect the respiratory tract through the common mucosal immune system, and respiratory tract flora disorders also affect the digestive tract through immune regulation. The effect is called the "gut-lung axis" $(20,21)$, which may further explain why patients with COVID-19 pneumonia often have digestive symptoms.

Curiously, our data indicate that patients with digestive symptoms in our case series rarely had underlying digestive diseases. Unlike other studies $(12,13)$, we did not find significant liver injury, which was similar to the findings of Wu et al. (22). It is difficult to speculate why there are variations in liver test abnormalities among studies, but these variations should be further investigated to better understand how and when COVID-19 affects the hepatic function. Nevertheless, we found that patients with digestive symptoms were more likely to exhibit elevated liver tests, such an AST and ALT, compared with patients without digestive symptoms. This is a topic worthy of attention.

We have noted that as the severity of the disease increases, digestive symptoms become more pronounced. One possibility is that digestive symptoms indicate viral load and replication within the gastrointestinal tract, which leads to more severe disease. Another possibility is that patients with extrapulmonary symptoms reported later for care because they did not initially have typical respiratory symptoms, and thus presented at a later and less curable stage of disease. These hypotheses deserve close examination in future research.

The present study has several limitations. First, our analysis was based on a retrospective study with a relatively small 
sample, which might cause bias and limit the reliability or generalizability of our results. Second, we did not test for RNA of SARS-CoV-2 in the stool of patients with COVID-19, so we cannot correlate digestive symptom prevalence and severity with the presence of viral RNA in stool specimens. Future research needs to focus on this relationship to further explore the prognostic value of stool testing as both a diagnostic and prognostic indicator in COVID-19. Third, blood biochemical examinations are based on a comparison of means in our study that not being subdivided to patients with individual abnormalities. Furthermore, a detailed analysis would be useful to mark some differences. Finally, given the dynamic nature of the current COVID-19 pandemic, the relationship between these patients' prognosis and digestive symptoms remains to be investigated with more data worldwide.

In summary, we have found that patients with COVID-19 are prone to digestive symptoms and nearly half report a digestive symptom in addition to fever and/or respiratory symptoms on presentation to the hospital. In rare instances, patient can even present with digestive symptoms in the absence of respiratory symptoms. Compared with COVID-19 patients without digestive symptoms, those with digestive symptoms have a longer time from onset to admission and evidence of more laboratory derangements, including prolonged coagulation and higher liver enzymes tests. These results obligate additional research evaluating the prevalence, incidence, predictors, and outcomes of digestive symptoms in this still emerging pandemic. In the meantime, clinicians must bear in mind that digestive symptoms, such as diarrhea, may be one among the presenting features of COVID-19; in some cases, they may arise before the respiratory symptoms, and on rare occasions, it is the only presenting symptom of COVID19. Clinicians should raise their index of suspicion when atrisk patients, such as those exposed to COVID-19, present with fever and digestive symptoms, even in the absence of respiratory symptoms. This knowledge may help with earlier identification of COVID-19, faster time to treatment, earlier quarantine, and lower exposure to bystanders.

\section{CONFLICTS OF INTEREST}

Guarantor of the article: Lei Pan, MD, PhD, Guogang Xu, MD, PhD, and Lei $\mathrm{Tu}, \mathrm{MD}, \mathrm{PhD}$, accept full responsibility for the conduct of the study.

Specific author contributions: Lei Pan, MD, PhD, Mi Mu, MD, and Pengcheng Yang, MD, contributed equally to this article. Conceiving and designing the experiments: L.P., G.X., L.T. Case collection: M.M., C.H., Y.J., R.P., Y.D., T.L., J.Y. Data Extraction: X.N., P.Y., Y.S., J.W., R.W. Statistical Analysis: L.P., H.G.R., M.M. Interpretation of results: P.L., B.H., G.X., Q.H., L.T. Writing and revising the paper: L.P., G.X., M.M., P.Y., Y.S. We thank Wuhan Medical Treatment Expert Group for COVID-19, Dr Hong Gang Ren and Prof Chengxia Liu for preparations of the manuscript.

Financial support: Beijing Municipal Natural Science Foundation (CN, 7192197), National Natural Science Foundation of China (CN, 81700490), Health and Family Planning Commission of Shandong Province (CN, 2017WS366), Traditional Chinese Medicine Administration Plan Project of Shandong Province (CN, 2019-0503), and Technology Plan Project of Binzhou Medical University (CN, BY2017KJ30).

Potential competing interests: None to report.

\section{Study Highlights}

\section{WHAT IS KNOWN}

COVID-19 is currently a pandemic that threatens global health.

Most patients with COVID-19 present with typical respiratory symptoms and signs.

However, early experience with the outbreak in Wuhan, China, revealed that many people experienced extrapulmonary digestive symptoms on presentation.

\section{WHAT IS NEW HERE}

$\checkmark$ Digestive symptoms are common in COVID-19 in addition to fever and respiratory symptoms and are reported in nearly half of patients presenting to the hospital. In rare cases, digestive symptoms may occur in the absence of any respiratory symptoms

When focusing only on diarrhea, in contrast to other digestive symptoms, $17 \%$ of patients with COVID-19 in this series reported loose stools on the initial presentation.

$\checkmark$ COVID-19 patients with digestive symptoms have a longer time from symptom onset to admission than that of patients without digestive symptoms; this may reflect diagnostic delay because typical respiratory symptoms were not initially predominant.

$\checkmark$ COVID-19 patients with digestive symptoms have laboratory evidence of prolonged coagulation and higher liver tests as compared to those without digestive symptoms, emphasizing the importance of including symptoms such as diarrhea to diagnose COVID-19 early.

\section{REFERENCES}

1. Phelan AL, Katz R, Gostin LO. The novel coronavirus originating in Wuhan, China: Challenges for global health governance. JAMA 2020;323: 709-10.

2. Wu Y, Ho W, Huang $\mathrm{Y}$, et al. SARS-CoV-2 is an appropriate name for the new coronavirus. Lancet 2020;395:949-50.

3. Legido-Quigley H, Asgari N, Teo YY, et al. Are high-performing health systems resilient against the COVID-19 epidemic? Lancet 2020;395: $848-50$.

4. Wang P, Anderson N, Pan Y, et al. The SARS-CoV-2 outbreak: Diagnosis, infection prevention, and public perception. Clin Chem 2020. [Epub ahead of print March 10, 2020].

5. Khot WY, Nadkar MY. The 2019 novel coronavirus outbreak-A global threat. J Assoc Physicians India 2020;68:67-71.

6. Wang D, Hu B, Hu C, et al. Clinical characteristics of 138 hospitalized patients with 2019 novel coronavirus-infected pneumonia in Wuhan, China. JAMA 2020;323:1061-1069.

7. Cascella M, Rajnik M, Cuomo A, et al. Features, Evaluation and Treatment Coronavirus (COVID-19). StatPearls: Treasure Island, 2020. [Epub ahead of print March 20, 2020].

8. Young BE, Ong SWX, Kalimuddin S, et al. Epidemiologic features and clinical course of patients infected with SARS-CoV-2 in Singapore. JAMA 2020. [Epub ahead of print March 03, 2020].

9. Chen N, Zhou M, Dong X, et al. Epidemiological and clinical characteristics of 99 cases of 2019 novel coronavirus pneumonia in Wuhan, China: A descriptive study. Lancet 2020;395:507-13.

10. Gao QY, Chen YX, Fang JY. 2019 novel coronavirus infection and gastrointestinal tract. J Dig Dis 2020. [Epub ahead of print February 25, 2020].

11. Huang C, Wang Y, Li X, et al. Clinical features of patients infected with 2019 novel coronavirus in Wuhan, China. Lancet 2020;395:497-506.

12. Yao N, Wang SN, Lian JQ, et al. Clinical characteristics and influencing factors of patients with novel coronavirus pneumonia combined with 
liver injury in Shaanxi region [in Chinese]. Zhonghua Gan Zang Bing Za Zhi 2020;28:E003.

13. Hu LL, Wang WJ, Zhu QJ, et al. Novel coronavirus pneumonia related liver injury: Etiological analysis and treatment strategy [in Chinese]. Zhonghua Gan Zang Bing Za Zhi 2020;28:E001.

14. Yang X, Yu Y, Xu J, et al. Clinical course and outcomes of critically ill patients with SARS-CoV-2 pneumonia in Wuhan, China: A singlecentered, retrospective, observational study. Lancet Respir Med 2020. [Epub ahead of print February 24, 2020].

15. Guan GW, Gao L, Wang JW, et al. Exploring the mechanism of liver enzyme abnormalities in patients with novel coronavirus-infected pneumonia [in Chinese]. Zhonghua Gan Zang Bing Za Zhi 2020;28:E002.

16. Tang A, Tong ZD, Wang HL, et al. Detection of novel coronavirus by RTPCR in stool specimen from asymptomatic child, China. Emerg Infect Dis 2020;26. [Epub ahead of print March 09, 2020].
17. Xie C, Jiang L, Huang G, et al. Comparison of different samples for 2019 novel coronavirus detection by nucleic acid amplification tests. Int J Infect Dis 2020;93:264-7.

18. Xiao F, Tang M, Zheng X, et al. Evidence for gastrointestinal infection of SARS-CoV-2. Gastroenterology 2020. [Epub ahead of print March 03, 2020].

19. Li M, Wang B, Zhang M, et al. Symbiotic gut microbes modulate human metabolic phenotypes. Proc Natl Acad Sci USA 2008;105:2117-22.

20. Budden KF, Gellatly SL, Wood DL, et al. Emerging pathogenic links between microbiota and the gut-lung axis. Nat Rev Microbiol 2017;15:55-63.

21. He Y, Wen Q, Yao F, et al. Gut-lung axis: The microbial contributions and clinical implications. Crit Rev Microbiol 2017;43:81-95.

22. Wu J, Liu J, Zhao X, et al. Clinical characteristics of imported cases of COVID-19 in Jiangsu province: A multicenter descriptive study. Clin Infect Dis 2020. [Epub ahead of print February 29, 2020]. 